\title{
Plano de Manejo da Floresta Nacional de Caxiuanã (PA): conflitos entre interesses de populações tradicionais e unidades de conservação
}

\author{
Plan de Gestión de la Floresta Nacionale de Caxiuanã (PA): \\ conflictos entre intereses de poblaciones tradicionales y \\ unidades de conservación
}

\section{Management plan of Caxiuanã National Forest (PA, Brazil): conflict between traditional populations interest and conservation units}

Lilian Vieira Miranda Garcia
lilian.miranda@icmbio.gov.br
Mestranda Programa de Pós-graduação em Geografia - UEPG

Elisana Milan

elisana.milan@gmail.com Doutoranda do Programa de Pós-graduação em Geografia - UEPG

Dinameres Aparecida Antunes dinameres@hotmail.com Doutoranda do Programa de Pós-graduação em Geografia - UEPG

Rosemeri Segecin Moro rsmoro@uepg.br Professora Doutora do Programa de Pós-graduação em Geografia - UEPG

Resumo: No Brasil a busca pelos direitos das populações tradicionais é recente, existindo diversos conflitos, como entre o plano de manejo e as populações tradicionais residentes em Unidades de Conservação (UC) e no seu entorno. Uma alternativa para a compreensão da problemática é a análise integradora geoecológica e esta norteou esta análise do Plano de Manejo da Floresta Nacional de Caxiuanã, uma unidade federal que abriga populações tradicionais ribeirinhas. Discute-se os direitos destas frente ao Sistema Nacional de Unidades de Conservação (SNUC) e conclui-se que a análise integrada dos elementos geoecológicos inexiste no Plano de Manejo, levado ao conflito entre o modo de vida dos ribeirinhos e os objetivos da UC.

Palavras-chave: Sistema Nacional de Unidades de Conservação. Geoecologia. Análise integrada. 
Resumen: La búsqueda de los derechos de las poblaciones tradicionales es reciente en Brasil y existen conflictos dentro y fuera de las áreas protegidas. Hay problemas entre poblaciones tradicionales que residen en Unidades de Conservación (UC) y el respectivo plan de gestión. Una posibilidad de solución es hacer un análisis integradora a través del Geoecología y por lo tanto, hemos tratado de estudiar el Plan de Gestión da Floresta Nacional de Caxiuanã, una unidad federal que alberga poblaciones tradicionales costeras Se discute sus derechos ante a la Sistema Nacional de Unidades de Conservación (SNUC) y se concluye que el análisis integrado de elementos geoecológicos fue inexistente en el Plan de Gestión y el modo de vida de los costeros y los objetivos de UC están en conflicto.

Palabras-Clave: Sistema Nacional de Unidades de Conservación. Geoecología. Análisis integrada.

abstract: In Brazil, the search for the right of traditional populations is something relatively new. There are several conflicts among traditional populations living in and out Conservation Units, corresponding to the management plans. In order to understand such problems one could use geoecological analysis so we have analyzed the Caxiuanã National Forest management plan that includes riverine traditional population. We discuss the population rights before the National System of Conservation Units (SNUC) and could conclude that lacks a full analysis from geoecological elements in the management plan so the living habits from the riverines and the goals from Conservation Units are indeed contradictory.

Keywords: National System of Conservation Units. Geoecology. Integrated analysis.

\section{INTRODUÇÃO}

As populações tradicionais brasileiras vivem em eterno conflito com a sociedade moderna. Ora pela legislação incapaz de se adaptar aos processos culturais e sociais das sociedades tradicionais, tampouco as especificidades de cada comunidade, ora pela profunda diferença de valores. Mesmo no interior de Unidades de Conservação (UC), espaços protegidos com o objetivo de conservação da biodiversidade, as populações tradicionais residentes buscam seus direitos diante de conflitos de ordem territorial e de manejo dos recursos naturais.

A Floresta Nacional de Caxiuanã, unidade de conservação de uso sustentável localizada no estado do Pará, tem como objetivo o uso racional dos recursos naturais e pesquisa científica. Há populações ribeirinhas residentes na área desde antes da criação da UC em 1961. O plano de manejo da Unidade somente foi publicado em 2013, e segue o Roteiro Metodológico para Elaboração de Plano de Manejo de Florestas Nacionais elaborado pelo ICMBio (Instituto Chico Mendes de Conservação da Biodiversidade), órgão gestor das Unidades de Conservação federais.

A complexidade do contexto apresentado solicita uma abordagem que foge do modelo compartimentado e reducionista. Assim, a Geoecologia, com sua busca pelo entendimento da totalidade e das inter-relações entre elementos pode trazer benefícios para o planejamento de áreas conflituosas. Para tanto, este artigo estrutura-se em duas sessões. 
Inicialmente, discute-se os conceitos de população tradicional e seus direitos adquiridos diante da legislação ambiental brasileira, principalmente, relacionada ao Sistema Nacional de Unidades de Conservação (SNUC). Além disso, contextualiza-se como a análise sistêmica geoecológica aproxima-se da lógica da construção do pensamento tradicional. Na segunda sessão, busca-se analisar o Plano de Manejo da FLONA de Caxiuanã, com o intuito de nele identificar elementos da geoecologia que poderiam facilitar o entendimento deste território tradicional.

Todos os dados aqui discutidos constam do Plano de Manejo da FLONA (ICMBIO, 2012) ou foram fruto de observação direta na unidade de conservação.

\section{ABORDAGEM LEGAL AMBIENTAL DAS POPULAÇÕES TRADICIONAIS}

A busca pelos direitos dos povos e populações tradicionais é recente no Brasil. A Convenção sobre Diversidade Biológica (CDB), assinada durante a Eco 92, reafirma a responsabilidade das Nações pela conservação de sua diversidade biológica e pela utilização sustentável de seus recursos naturais, tendo como dever respeitar, preservar e manter o conhecimento, inovação e práticas das comunidades tradicionais e indígenas. (MMA, 2000).

A criação de Unidades de Conservação com o intuito de promover a proteção aos meios de vida e a cultura das populações tradicionais, assegurando o uso sustentável dos recursos naturais, foi reflexo principalmente da luta dos seringueiros por seu território. Nesse contexto, as primeiras Reservas Extrativistas (RESEX), categoria de Unidade de Conservação com tal objetivo, foram instituídas no Brasil na década de 90. (AGUIAR; MOREU; FONTES, 2011).

O SNUC, criado para organizar a criação e gestão das UC brasileiras, permite a presença de populações tradicionais em outras categorias de Unidades de Conservação além das RESEX, como é o caso das Florestas Nacionais (FLONAs). Cabe destacar que tal categoria tem como um de seus objetivos a exploração florestal sustentável: "Nas FLONAS é admitida a permanência de populações tradicionais que a habitam quando de sua criação, em conformidade com o dispositivo em regulamento e no Plano de Manejo da Unidade". (ICMBIO, 2009a, p.16).

Mesmo sendo utilizado para nortear a elaboração do SNUC, o conceito de populações tradicionais não é apresentado com clareza no texto da lei. Segundo Rodrigues (2005), o conceito originalmente inserido na legislação foi revogado acertadamente por ser muito abrangente e podendo ser atribuído, com pouco esforço, a toda população brasileira. Para a primeira versão da lei do SNUC populações tradicionais são:

Grupos humanos culturalmente diferenciados, vivendo há no mínimo, três gerações em um determinado ecossistema, historicamente reproduzindo seus modos de vida, em estreita dependência do meio natural para sua subsistência e utilizado os recursos humanos de forma sustentável. (BRASIL, 2000, p.48). 
Já Diegues (2000) utiliza-se da expressão "sociedades tradicionais" para definir grupos humanos culturalmente diferenciados que historicamente reproduzem seu modo de vida, de forma mais ou menos isolada, com base em modos de cooperação social e formas específicas de relações com a natureza, caracterizadas tradicionalmente pelo manejo sustentado do meio ambiente.

Em 2004 foi criada a Comissão Nacional de Desenvolvimento Sustentável das Comunidades Tradicionais, constituída basicamente por órgãos de governo. Em 2006, já renomeada para Comissão Nacional de Desenvolvimento Sustentável dos Povos e Comunidades Tradicionais, teve inseridos como membros representações sociais das próprias populações como redes, associações e conselhos. A legislação brasileira para proteção dessas populações foi tomando forma até culminar na Política Nacional de Desenvolvimento Sustentável dos Povos e Comunidades Tradicionais (PNPCT) promulgada em 2007 (SHIRAISHI, 2007). Deste modo para Brasil (2007) povos e comunidades tradicionais:

São grupos culturalmente diferenciados e que se reconhecem como tais, que possuem formas próprias de organização social, que ocupam e usam territórios e recursos naturais como condição para sua reprodução cultural, social, religiosa, ancestral e econômica, utilizando conhecimentos, inovações e práticas gerados e transmitidos pela tradição.

Embora a legislação brasileira, no que se refere à proteção dos povos e comunidades tradicionais, tenha apresentado avanços importantes nos últimos anos, existe ainda uma distância entre as regras impostas pela sociedade moderna e as necessárias para desenvolvimento e conservação sociocultural das populações tradicionais. No interior das UC, os conflitos entre as duas linhas de pensamento ficam evidentes: a legislação ambiental, reflexo da construção do pensamento moderno, frente aos modos de vida tradicionais, fruto do desenvolvimento da cultura especifica de cada população.

Para Strauss (2008) a construção do conhecimento tradicional é consequência da visão de mundo das populações que consideram religião, natureza e homem como um único elemento, e além da busca pela satisfação coletiva do corpo é imprescindível a busca pela satisfação do espírito. Portanto, o manejo tradicional não segue necessariamente a mesma lógica do manejo moderno, este último conceituado pelo ICMBio (2009a, p.2) como "todo procedimento que visa assegurar a conservação da diversidade biológica e dos ecossistemas".

Os planos de manejo das Unidades de Conservação são documentos técnicos destinados a estabelecer as normas de uso das áreas e do manejo dos recursos. No caso de UC com populações residentes, é assegurada sua ampla participação mediante os conselhos deliberativos quando RESEX ou Reservas de Desenvolvimento Sustentável (RDS) e conselhos consultivos quando FLONAs e demais categorias (SNUC, 2000). No entanto, o conhecimento tradicional ainda é pouco utilizado no manejo das Unidades de Conservação brasileiras. (WWF; IPE, 2012). A aproximação de conhecimento tradicional e conhecimento científico sugere uma visão sistêmica de preservação e trabalhar de modo isolado é ir contra toda a tendência de transversalidade. 
Dentre os objetivos do plano de manejo de FLONAs preconizados pelo ICMBio está:

Estabelecer, quando couber, normas e ações específicas visando compatibilizar a presença das populações tradicionais residentes com os objetivos da Unidade de Conservação. Nos casos em que não for possível manter a população residente dentro da Floresta Nacional, a presença da mesma será tolerada mediante regras e ações específicas até que seja possível sua indenização ou compensação e realocação. (ICMBio, 2009b, p.11).

Destaca-se que o objetivo da categoria da UC, isto é o uso múltiplo sustentável, sobrepõe aos modos de vida das populações residentes. No entanto, uma das características do planejamento das FLONAs é o aspecto participativo tanto na sua elaboração quanto na implementação. (ICMBIO, 2009b).

\section{ABORDAGEM GEOECOLÓGICA EM UNIDADES DE CONSERVAÇÃO}

Uma ciência baseada em modelos reducionista dificilmente será capaz de explicar os elementos e inter-relações contidos em um território tradicional, tampouco embasar seu planejamento. Para Feyrabend (1977) devemos extrapolar as barreiras impostas pela ciência moderna, refutando a separação do conhecimento em campos de pesquisa, pois o estudo de meios complexos demandam procedimentos complexos. Morin vai além, afirmando que o paradigma da complexidade:

Somente incitar a estratégia/inteligência do sujeito pesquisador a considerar a complexidade da questão estudada. Incita a distinguir e fazer comunicar em vez de isolar e de separar, a reconhecer os traços singulares, originais, históricos do fenômeno em vez de ligá-los pura e simplesmente a determinações ou leis gerais, a conceber a multiplicidade de toda entidade em vez de a heterogeneizar em categorias separadas ou de a homogeneizar em indistinta totalidade. Incita a dar conta dos caracteres multidimensionais de toda realidade estudada. (MORIN, 2005, p.334).

Sotchava, nos anos 60, ao definir o conceito de geossistema redefine a concepção de paisagem, que passa a ser considerada como uma formação sistêmica formada por cinco atributos fundamentais: estrutura, funcionamento, dinâmica, evolução e informação, articulando a análise espacial, própria da Geografia, com a análise funcional própria da Ecologia. (SILVA, 2008).

A aplicabilidade da análise geoecológica não se direciona apenas a ambientes naturais, mas envolve também a paisagem como reflexo/aspecto externo de uma área ou território, acrescentando a interpretação da paisagem como sistema econômico-social e como unidade espacial decorrente da cultura desenvolvida ao longo do tempo. (SILVA, 2012). Na Geoecologia, a visão da paisagem é antroponatural, transtemporal e sistêmica. Este ramo do conhecimento busca a compreensão dos sistemas naturais e sua dinâmica numa análise natural e antrópica, considerando a regionalização físico-geográfica e o desenvolvimento histórico da paisagem. 
A abordagem geoecológica oferece uma contribuição essencial na compreensão dos sistemas naturais e sua dinâmica. Fundamenta-se numa visão geossistêmica alicerçada numa análise integrada dos componentes antrópicos e naturais, que dá-se pela caracterização socioeconômica e geoecológica. Essa análise geossistêmica é baseada no conceito de paisagem onde seus elementos integrantes, tais como aspectos naturais, socioeconômicos, territoriais e culturais, buscam representar um sistema de relações progressivamente mais complexas. (BARROS, 2011).

\section{ANÁliSE DO GEOSSISTEMA FLONA CAXIUANÃ A PARTIR DE SEU PLANO DE MANEJO}

Segundo o SNUC, as FLONAs são áreas com cobertura florestal de espécies predominantemente nativas com objetivo de uso múltiplo sustentável dos recursos florestais e pesquisa científica, onde é "tolerada" a permanência de populações tradicionais que a habitam quando de sua criação e visitação pública condicionada às normas do Plano de Manejo. (ICMBIO, 2009a).

A criação da FLONA de Caxiuanã se deu por recomendação de pesquisadores da Organização das Nações Unidas para a Agricultura e a Alimentação (FAO) com o objetivo de promover o manejo florestal. Os objetivos das Florestas Nacionais foram sendo reformatados ao longo dos anos, de acordo com as mudanças na legislação ambiental federal, sendo que atualmente o parâmetro legal utilizado na gestão e manejo da UC é o SNUC, o qual prevê que o cumprimento dos objetivos seja pautado no Plano de Manejo da área. (ICMBIO, 2012).

A Floresta Nacional de Caxiuanã (Figura 1), situada nas proximidades da Baía de Caxiuanã está localizada entre os rios Xingu e Tocantins. (BRASIL, 1961). A Unidade de Conservação possui área de aproximadamente 318.000 hectares, na mesorregião do Marajó, no Pará ( $\left.2^{\circ} 15^{\prime} \mathrm{S} 52^{\circ} \mathrm{W} / 1^{\circ} 30^{\prime} 51^{\circ} 15^{\prime} \mathrm{W}\right)$, estando 59\% da UC no município em Portel e $41 \%$ no município de Melgaço. A FLONA dista aproximadamente $400 \mathrm{~km}$ de Belém, que só podem ser percorridos por via fluvial (16 horas) ou aérea (1 hora). (ICMBIO, 2012)

Somente em 2013, mais de 60 anos após a criação da UC, foi publicado o Plano de Manejo da Unidade, elaborado conforme o Roteiro Metodológico para elaboração dos Planos de Manejo de Florestas Nacionais. (ICMBIO, 2009b).

A elaboração do documento que norteia a gestão da UC foi realizada pelo ICMBio em parceria com Serviço Florestal Brasileiro (SFB) e Museu Emilio Goeldi. Utilizou-se metodologias participativas como o mapa falado, para identificação das áreas de uso das populações residentes e definição do zoneamento da unidade. Outro aspecto a se destacar é o mapeamento das áreas destinadas para exploração florestal não comunitária que totalizam aproximadamente 183.000 hectares. (ICMBIO, 2012). 


\section{COMPONENTES BIÓTICOS E ABIÓTICOS}

A região amazônica conta com uma das maiores biodiversidades do mundo, com altos índices de endemismo e novas ocorrências a cada pesquisa, devido a vários fatores favorecedores como o clima tropical, a densa hidrografia, a posição geográfica, entre outros.

A UC objeto deste artigo está inserida no Bioma Amazônico, possui tipologias de Floresta Ombrófila Densa de Terras Baixas, Floresta Ombrófila Densa Aluvial (floresta de várzea e de igapó), Campinarana e pequena mancha de Cerrado. Segundo dados do Plano de Manejo, nestas florestas destacam-se algumas espécies de uso especial como a seringueira, castanheira, babaçu, piassava e sorva, além de outras de valor madeireiro e/ ou ameaçadas de extinção. (ICMBIO, 2012).

Quanto à fauna, foram registradas 1.804 espécies distribuídas nos mais diversos grupos biológicos, destacando-se espécies-chave como tamanduá-bandeira, onça-pintada, macaco-de-cheiro, macaco-prego, peixe-boi, boto-cinza e boto-vermelho, lontra, capivara, peixe-boi-amazônico, tamanduás, preguiças, além de números expressivos de espécies de aves e anfíbios e a mais rica ictiofauna do mundo. (ICMBIO, 2012).

Na FLONA de Caxiuanã existem duas estações bem distintas ao longo do ano: a estação chuvosa, entre os meses de dezembro a maio e a estação menos chuvosa (ou seca) que se estende de junho a novembro. A classificação segundo Köeppen para a área é do tipo Am, ou seja clima de monção, com precipitação excessiva durante alguns meses e uma curta estação seca. A precipitação distribui-se em 76,3\% do total anual na estação chuvosa e $23,7 \%$ na estação seca, podendo alcançar uma média anual de $2.107 \mathrm{~mm}$. A temperatura média anual é aproximadamente $26^{\circ} \mathrm{C}$, com picos no período de seca e valores médios menores no período chuvoso. A umidade relativa do ar também varia de acordo com as diferentes estações de seca e cheia, mas o valor médio anual é de aproximadamente $82 \%$. (ICMBIO, 2012).

A FLONA se distribui em terrenos de baixa altitude, variando entre 0 a $80 \mathrm{~m}$, com predominância de Latossolos com elevado nível de drenagem e baixa fertilidade natural, além de pequenas manchas de Neossolos e Gleissolos. (ICMBIO, 2012).

Localizada no interflúvio dos rios Xingu e Tocantins, a Floresta Nacional de Caxiuanã está inserida em quatro bacias hidrográficas: Caxiuanã, Caquajó ou Tapacu, Cariatuba e Pracupi. Todos os cursos desaguam na Baía de Caxiuanã e são formadas por rios de águas negras e ácidas. O período de enchente é entre os meses de janeiro a maio e o período de vazante ocorre entre maio e julho. (ICMBIO, 2012).

\section{ASPECTOS TERRITORIAIS}

A situação fundiária da FLONA de Caxiuanã é complexa, uma vez que o decreto de criação previa a desapropriação das áreas, a qual não ocorreu de imediato. (BRASIL, 1961). Passados 25 anos de sua criação, o Instituto Brasileiro de Desenvolvimento Florestal 
(IBDF) iniciou sem sucesso, a regularização fundiária com indenização e retirada dos ocupantes, sendo que muitos permanecem ainda na UC.

A FLONA (Figura 1) faz limite com outras áreas protegidas como a RESEX GurupáMelgaço, Comunidades Remanescentes de Quilombos de Gurupá e assentamentos como Projeto Estadual de Assentamento Agroextrativista (PAE) Camutá do Pucuruí e o PAE Majari I. Com a proximidade a outras comunidades tradicionais, o território da UC se sobrepõe a áreas de uso das populações do entorno, o que também é um potencial gerador de conflitos.

Figura 1 - Localização da Floresta Nacional de Caxiuanã e de territórios instituídos pelo poder público no seu entorno

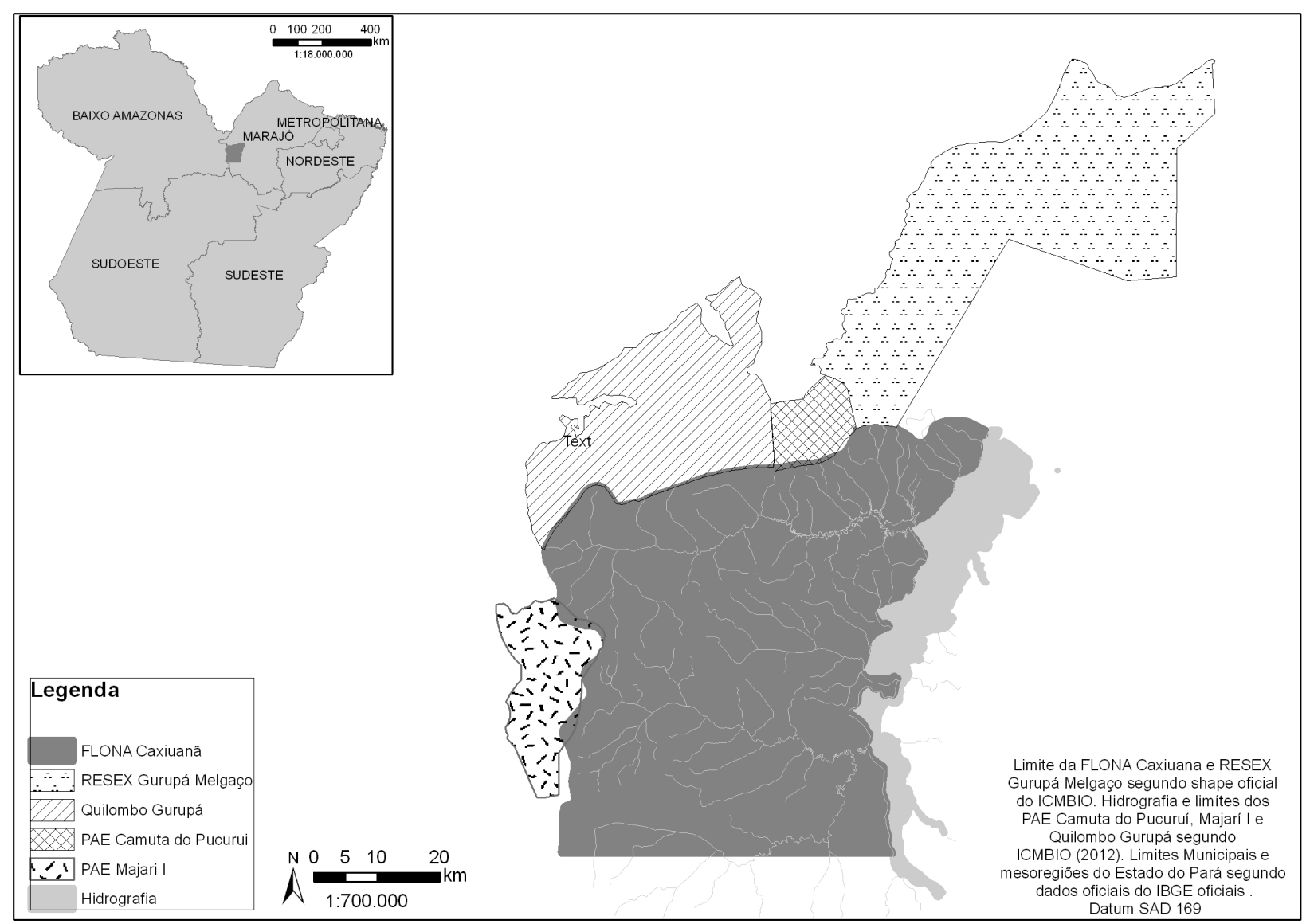

Fonte: Os autores

\section{COMPONENTES SOCIOECONÔMICOS}

A população da FLONA de Caxiuanã tem origem indígena na sua maioria e também na miscigenação com escravos africanos, portugueses, ingleses e holandeses em menor quantidade, com população feminina ligeiramente maior que a masculina e $70 \%$ dos residentes com faixa etária de até 35 anos de idade, portanto é uma população jovem. (ICMBIO, 2012). 
Semelhante a outras comunidades ribeirinhas, as cinco comunidades localizadas na FLONA de Caxiuanã estão posicionadas a margem de rios e igarapés: Caxiuanã, Pedreira e Laranjal (Baía de Caxiuanã), Pracupi e Cariatuba (Quadro 1.). As três primeiras são periféricas à baía de Caxiuanã e as duas seguintes situam-se mais ao sul na FLONA, nas bacias dos rios Pracupí e Cariatuba. O Plano de Manejo afirma que não há registros do fator pelo qual estas famílias foram autorizadas a permanecer na FLONA após o período de desapropriações, tampouco as famílias tem com clareza a razão deste fato. (ICMBio, 2012).

Quadro 1 - Localização e habitantes da Floresta Nacional de Caxiuanã, PA

\begin{tabular}{|c|c|c|c|}
\hline Comunidade & localização & N. de famílias & $\begin{array}{l}\text { N. de } \\
\text { indivíduos }\end{array}$ \\
\hline Caxiuanã & Rio Curuá & 24 & 110 \\
\hline Pedreira & Rio Camoin & 12 & 55 \\
\hline Laranjal & Rio Laranjal & 13 & 62 \\
\hline Cariatuba & Rio Cariatuba & $\begin{array}{l}\text { Pequeno número (não detectado) em várias localidades dispersas } \\
\text { (Cedro, Castanhal, Terra Preta) }\end{array}$ & 71 \\
\hline Pracupi & Rio Pracupi & $\begin{array}{c}31 \text { famílias em várias localidades (São Francisco, Anjo da Guarda, } \\
\text { Igarapé Grande e São Tomé) }\end{array}$ & 107 \\
\hline & 405 \\
\hline
\end{tabular}

Fonte: ICMBio (2012)

A Comunidade Caxiuanã difere em relação às outras comunidades por apresentar maior proximidade com a Estação Científica Ferreira Penna (ECFP), que possui 45\% de seus funcionários moradores nessa comunidade. Esta comunidade possui uma escola de ensino fundamental, um barco comunitário, um templo religioso evangélico e uma Associação de moradores. As demais comunidades possuem algumas infraestruturas precárias. Os moradores não possuem atendimento básico de saúde, sendo atendidos na enfermaria da Estação Científica quando há pequenas ocorrências ou nas sedes municipais mais próximas, Portel, Melgaço ou Senador José Porfírio, dependendo da localização da comunidade. (ICMBIO, 2012).

\section{MODO DE VIDA DOS RIBEIRINHOS DE CAXIUANÃ}

A agricultura de subsistência, com produção da farinha de mandioca, é a base do sustento das populações residentes de Caxiuanã, exercendo complementação com extrativismo vegetal e animal. O sistema de produção das comunidades é feito de modo rudimentar, está formado por diversas atividades ao longo do ano, incluindo agricultura com mão de obra familiar, a coleta do açaí e da castanha, óleo, resinas, breus, frutos, extração de palmito e madeira. As atividades no roçado são divididas, e em grande parte a mulher é a responsável pelo seu cuidado. Em épocas de preparação da terra e colheita, homens e crianças também ajudam. São várias as espécies cultivadas, no entanto estas se diferenciam entre as comunidades. O cultivo também está relacionado a crenças 
religiosas, sendo realizados plantios em dias de santos como dia 13 de dezembro, que é o dia de Santa Luzia, e 21 de dezembro, de São Tomé, que é o dia mais produtivo segundo a população. (ICMBIO, 2012).

As atividades de pesca se caracterizam como uma prática exercida principalmente pelos mais jovens, e além de ser uma fonte de sustento também é exercida enquanto esporte e lazer. A pesca tradicional utilizando-se de substancias tóxica é proibida, no entanto ainda é realizada ocasionalmente nas comunidades, onde se lança um extrato do timbó-urucu que mata os peixes e facilita a pesca. (ICMBIO, 2012).

O isolamento da FLONA de Caxiuanã faz com que o comércio seja quase inexistente, no entanto há regatões que vão até as localidades negociar a compra de castanhas-do-pará. Apenas na comunidade de Caxiuanã há venda de castanhas e açaí para os pesquisadores e funcionários da Estação Cientifica, bem como de farinha de mandioca. (ICMBIO, 2012).

A energia elétrica inexiste nas comunidades, sendo o suprimento feito a partir de placas fotovoltaicas (energia solar) em aproximadamente $50 \%$ das casas da baía de Caxiuanã e mediante lamparinas e baterias no restante das comunidades da FLONA. (ICMBIO, 2012).

O abastecimento de água é oriundo dos rios e de poços próprios, que são incipientes. Na baía de Caxiuanã, cerca de 30\% da comunidade possui encanamento comunitário. Não há saneamento básico e os sanitários encontram-se em condições precárias e rústicas, onde seu conteúdo é lançado no solo ou diretamente no rio. As doenças mais comuns na região são de veiculação hídrica, relacionadas à falta de saneamento, principalmente diarreias e verminoses.

A população recorre aos conhecimentos tradicionais de medicina popular e aos seus quintais e canteiros de plantas medicinais cultivadas. O conhecimento dos poderes de cura das plantas medicinais pelos moradores mais antigos de Caxiuanã tem sido repassado ao longo do tempo para os mais jovens, também acrescidos por receitas veiculadas em rádio e televisão. As parteiras ainda são as principais detentoras do conhecimento médico, sendo bastante consideradas também como lideranças espirituais nas comunidades. (ICMBIO, 2012).

Quanto à educação, o ensino se estende somente até a $8^{\mathrm{a}}$ série do ensino fundamental, em salas multisseriadas, o que dificulta o aprendizado e o rendimento é muito baixo. A principal razão é a dificuldade de deslocamento do aluno, pois os barcos escolares são insuficientes ou falta combustível. (ICMBIO, 2012).

As práticas são tradicionalmente repassadas de geração a geração, sendo que os homens conhecem bem a floresta, rios e igarapés, sendo capazes de se deslocar com facilidade, apontando plantas e animais. Coletam somente para o consumo e o único item que é extraído para comercialização é a castanha-do-pará. (ICMBIO, 2012).

O ICMBio realiza cursos voltados às comunidades ribeirinhas da FLONA de Caxiuanã a partir da demanda dos próprio moradores. Os cursos visam orientar o desenvolvimento da região por meio da capacitação dos comunitários. Entre os diversos temas estão: associativismo, planejamento agroextrativista, projetos comunitários, 
sistemas agroflorestais (SAFs), criação de pequenos animais, beneficiamento da produção e adubação verde. A única atividade de visitação existente atualmente é a científica monitorada, por pesquisadores e alunos em cursos de campo realizados pelo ICMBio ou pelo Museu Paraense Emílio Goeldi (MPEG). (ICMBIO, 2012).

\section{RELAÇÃO ENTRE AS COMUNIDADES RIBEIRINHAS E A FLONA}

As comunidades residentes na FLONA têm uma relação intrínseca com o ambiente que as rodeia e ao qual pertencem, retirando dele praticamente tudo que precisam. $\mathrm{O}$ seu sustento é baseado na agricultura de subsistência, pesca e caça, bem como atividades extrativistas como a coleta de açaí, castanhas, em grande parte para o consumo próprio.

A influência externa se faz presente nas comunidades, alterando gradativamente hábitos e práticas, como é o caso das telhas de palha que estão sendo substituídas pelas de amianto e o número de moradores de Caxiuanã que trabalham para a Estação Cientifica. (ICMBIO, 2012).

Grande parte, $90 \%$ aproximadamente, das famílias tem conhecimento da existência da FLONA e do ICMBio/IBAMA. Este conhecimento é inevitável em função dos seus mais de 50 anos de criação, tendo essa a convivência permeado algumas gerações. (ICMBIO, 2012). Pelo menos $40 \%$ da população já ouviram falar do Plano de Manejo da FLONA, no entanto não sabem defini-lo com precisão, variando suas respostas entre "conservar a natureza", "proibir coisas para o bem de todos", "fiscalizar a área da FLONA", "fiscalizar as áreas de desmatamento". Desconhecem, no entanto as possibilidades de exploração madeireira e de outros produtos que existem em quantidades comercializáveis.

Falta o entendimento de que o Plano de Manejo, no caso de uma FLONA, é um instrumento que permite a exploração de recursos de forma sustentada, de modo a garantir a conservação dos elementos que compõe os ecossistemas, proteja os mais raros e vulneráveis e traga alguma melhoria na qualidade de vida nas pessoas da região de Caxiuanã que estarão envolvidas. (ICMBIO, 2012). De modo geral as comunidades acreditam que o Plano de Manejo da FLONA é algo que pode solucionar os seus problemas, o que cria grande expectativa entre eles. Estas expectativas estão ligadas a atribuições do Estado na melhoria de condições de vida, por meio de geração de empregos, instalação de sistema de água e saneamento, educação entre outros, o que não é responsabilidade direta da UC. Também acreditam que a existência da FLONA reduz a problemática do conflito de terra e de poluição ambiental e aumenta a possibilidade de melhoria das condições de vida nas comunidades, bem como contribui para a manutenção das populações tradicionais, para o aumento da segurança e a conservação florestal. (ICMBIO, 2012)

Por outro lado, viver nas proximidades ou no polígono de uma FLONA levanta situações de temor e insegurança. Quando incitado a fazer uma mapa falado da FLONA, algumas comunidades declararam não utilizar áreas na FLONA para nada. Porém, após terem contato com mapas falados de outras comunidades, admitiram que utilizavam as áreas. (ICMBIO, 2012). 


\section{USO MÚLTIPLO, CONFLITANTE E ILEGAL NO INTERIOR DA FLONA}

A FLONA é um importante local no cenário nacional e internacional para as pesquisas sobre a biodiversidade da Amazônia e há diversos projetos de pesquisas são realizados. A partir da inauguração da Estação Científica Ferreira Penna em 1993, a maior parte das pesquisas desenvolvidas na FLONA utiliza esta base de apoio para os trabalhos de campo, com infraestrutura construída com recursos provenientes do Acordo de Cooperação entre os governos brasileiro e britânico. (ICMBIO, 2012).

Pesquisas podem ser feitas em toda a extensão da UC dependendo da autorização da gestão da Unidade por meio do Sistema de Autorização e Informação em Biodiversidade (SISBIO), no entanto os estudos estão concentrados nas áreas próximas à Estação Cientifica.

Quanto às atividades conflitantes ou ilegais destacam-se a pesca, caça e extração de madeiras. A pesca ilegal ocorre intensivamente ao longo do rio Anapú (o qual na sua margem esquerda delimita a UC), nas baías de Caxiuanã e dos Botos (no limite imediato da FLONA), além dos rios e igarapés do interior da FLONA. Na maioria dos igarapés dentro da FLONA os pescadores ilegais ancoram suas embarcações grandes às margens do Rio Anapú e adentram os igarapés com canoas. A escassez de peixe na região de Caxiuanã é atribuída à ação dos barcos comerciais que realizam pesca nas proximidades da comunidade e que, segundo os moradores, reduzem os estoques pesqueiros. Para os ribeirinhos, o ICMBio deveria realizar monitoramento e fiscalização permanente nessas áreas. (ICMBIO, 2012).

Quanto à caça existem diversos relatos de caçadores clandestinos, inclusive na comunidade Caxiuanã onde está localizada a base do ICMBio. Mais distante, nos Rios Pracupí e Cariá, o assunto é tratado abertamente e a caça é realizada por intrusos para comercialização da carne, uma vez que trazem tonéis e preparam salmoura em seus barracões. Existe também a caça realizada pelas comunidades tradicionais como atividade de subsistência. Todos os moradores do entorno da FLONA Caxiuanã afirmam não comercializar a caça, mas ainda assim a pressão sobre os animais caçados é grande, porque todas as famílias entrevistadas admitem consumir caça periodicamente. De acordo com depoimentos, mesmo quando uma família não caça ela recebe de outras os animais e garante, dessa forma, a dieta de proteínas. Entre as classes de animais caçados, a pressão maior é sobre os mamíferos ( $88 \%$, principalmente os grandes como anta, onça e veado), em seguida os répteis ( $8 \%$ ) e as aves $(4 \%)$. (ICMBIO,2012).

Entre o entorno e o interior da FLONA, nota-se considerável diferença na caça, que pode ser creditada ao cerceamento imposto pela legislação ambiental aos moradores da FLONA Caxiuanã. Enquanto o morador do interior da FLONA obedece a rigorosa fiscalização e só caça para a alimentação da família, os dados do entorno indicam que a caça é praticada livremente, sem censura a nenhuma espécie. (ICMBIO, 2012).

Enquanto os moradores da FLONA estão submetidos à legislação ambiental que restringe suas atividades, os moradores do entorno têm alimentação abundante e exercem o extrativismo animal e vegetal sem restrições. O mesmo ocorre com a madeira, 
as regiões ao sul e oeste da FLONA são os locais mais suscetíveis à exploração florestal madeireira, em função da menor vigilância decorrente do difícil acesso. Além disto, 54\% dos comunitários de Cariatuba e Pracupí afirmam ter experiência com a atividade madeireira. Já na região da baía de Caxiuanã, a extração da madeira é desenvolvida há 25 anos, mas foi reduzida substancialmente a partir do momento em que as comunidades do Laranjal e Pedreira passaram a ser consideradas parte da FLONA Caxiuanã. Esta atividade é realizada nos ambientes de várzea e de terra firme apenas pelos ribeirinhos que residem fora dos limites da FLONA, feita geralmente por encomenda.

Ao contrário da utilização medicinal e alimentícia, o Plano de Manejo considera a exploração da madeira uma atividade danosa, ainda que não seja voltada para comercialização, porque elimina os indivíduos que são explorados, ainda mais se consideradas as centenas de residências que se utilizam de madeira para os mais diferentes fins, somados a uma atividade exploratória clandestina.

Inúmeros moradores citaram que existe atividade exploratória para fins comerciais, mas asseguraram não estarem envolvidos. Entre as madeiras exploradas algumas são de notável valor comercial como o angelim-vermelho, acapu, angelim-rajado, angelim-pedra, cupiúba, maçaranduba e marupá. Outras espécies que ocorrem no entorno são consideradas em extinção e pelo menos no caso do pau-amarelo desapareceram há muitas décadas do circuito de comercialização pela destruição de grandes populações de árvores desta espécie das frentes de exploração. Outra espécie valiosa, que vinha sendo maciçamente explorada até a sua proibição é a ucuuba ou virola. (ICMBIO, 2012).

\section{CONSIDERAÇÕES FINAIS}

Na análise do Plano de Manejo da Floresta Nacional de Caxiuanã podem-se identificar elementos de suma importância para uma abordagem geoecológica, no entanto tais componentes não são inter-relacionados, tendo aspecto isolado e não contribuindo, efetivamente, para a compreensão da totalidade do sistema.

No Plano de Manejo da FLONA foram encontradas situações flagrantes de contradição entre os dados e o discurso. Pode-se aventar que partes do documento foram escritas por membros de equipes diferentes, sem o necessário consenso, como se depreende a seguir.

Se por um lado afirma que apenas 405 indivíduos habitam uma área de 318.000ha, por outra afirma que a exploração de madeira "não comercial" por estas comunidades é danosa. Entende-se que a aglomeração das comunidades concentra os impactos da exploração madeireira, no entanto se a se tal uso é considerado uma atividade tradicional para algumas comunidades o fomento à de técnicas de mínimo impacto deve ser estimulado, com o intuito de manter seus modos de vida.

Também percebe-se que, a seguir toda uma caracterização socioeconômica bastante detalhada e elucidativa, as alternativas de desenvolvimento sustentável aventadas, em sua maioria, seguem o estereótipo ecoturismo/artesanato/bionegócios (fármacos, 
cosméticos, inseticidas). É fato que existem experiências bem sucedidas nestas atividades, porém para a FLONA de Caxiuanã estas não foram mencionadas como atividades tradicionais ou mesmo familiares às comunidades. Assim um passo essencial no desenvolvimento de atividades não tradicionais é a consulta as comunidades objetivando levantar se as próprias populações considerariam esta mudanças de atividades desejável ou viável.

Enquanto o repertório de cursos oferecidos pelo ICMBio visa à capacitação do ribeirinho na otimização da produção familiar como sistemas agroflorestais, beneficiamento de produção, capacitação comunitária, entre outros, o Plano de Manejo menciona expressamente a necessidade de mapeamento e pesquisa de recursos da flora e fauna visando a patente de produtos rentáveis.

O que se vislumbra como alternativa para a conservação (da biodiversidade) é a completa subversão de valores de uma sociedade pré-industrial para a lógica de mercado.

O Plano de Manejo comenta, a respeito da reivindicação das populações tradicionais ao direito de permanecer em suas terras, sob seu modo de vida ancestral:

Baseia-se em um pacto que poderia ser chamado de neotradicionalismo. O que se supõe das populações tradicionais é um passado não predatório de uso de recursos naturais; o que se espera deles é que levem um modo de vida coerente com a conservação da diversidade biológica. Surge assim um pacto materializado em leis e dispositivos como as concessões de uso e planos de uso. (Cunha; Almeida, 1999 apud ICMBio, 2012).

A legislação brasileira, mesmo com os avanços dos últimos anos, não fomenta em sua plenitude a perpetuação plena dos modos de vida das populações tradicionais. As normas que regem a sociedade pós-moderna não seguem a mesma lógica da construção do conhecimento tradicional, e por consequência dos métodos de manejo dos recursos naturais utilizados pelas populações tradicionais. Os planos de manejo, de modo geral, limitam a aplicação do conhecimento tradicional das comunidades, que no entanto tem o direito constitucional reconhecido de continuar a viver a sua maneira, mantendo sua cultura e subsistência.

Além disso, no caso da Floresta Nacional de Caxiuanã, constatou-se a participação efetiva da população residente, porém a categoria da UC, no caso FLONA, não tem como objetivo principal a proteção aos modos de vida das populações tradicionais e em caso de conflito de usos, as regras do SNUC sobrepõem a conservação da biodiversidade sobre o modo de vida das populações tradicionais.

Aqui conclui-se que a rigidez do SNUC, aliado a falhas na categorização das unidades de conservação, dificulta a gestão e a conservação do modo de vida de populações tradicionais residentes em áreas protegidas, quando essas não apresentam como objetivo principal a proteção de sua cultura. 


\section{REFERÊNCIAS}

AGUIAR, Paulo Cesar Bahia de Aguiar; MOREAU, Ana Maria Souza dos Santos; FONTES, Ednice de Oliveira. Impactos na dinâmica ambiental do município de Canavieiras (BA) tendo a RESEX como fator de influência. Rev. Geomae, v.2, n.1, p.61-78, 2011.

BARROS, Luciana Lira. Aplicações da geoecologia da paisagem no planejamento ambiental e territorial dos parques urbanos brasileiros. Revista Geográfica de América Central, n. especial EGAL, p. 1-14, 2011.

BRASIL. Decreto $\mathbf{n}^{\circ}$ de 26 de novembro de 1961. Cria a Floresta Nacional de Caxiuanã. Disponível em <http://www.icmbio.gov.br/portal/images/stories/imgs-unidades-coservacao/flona_caxiuna.pdf>. Acesso em: 22 nov. 2013.

Lei 9.985 de18 de julho de 2000. Texto e vetos da Presidência da República ao Poder Legislativo. 2.ed. São Paulo: Conselho Nacional da Reserva da Biosfera da Mata Atlântica, 2000. 76p.

Decreto $\mathrm{n}^{0} 6440$ de 07 de fevereiro de 2007. Institui a Política Nacional de Desenvolvimento Sustentável dos Povos e Comunidades Tradicionais. Disponível em <http://www.planalto.gov.br/ ccivil_03/_ato2007-2010/2007/decreto/d6040.htm>. Acesso em: 26 nov. 2013.

ICMBIO. Instituto Chico Mendes de Biodiversidade. Lei 9985 de 18 de junho de 2000. Cria o Sistema Nacional de Unidades de Conservação e da outras providencias. Legislação ICMBio. Brasília, 2009a. v. 1, p. 7-29.

Roteiro metodológico para planos de manejo de Florestas Nacionais. Brasília: MMA, 2009b, 57p.

Plano de Manejo da Floresta Nacional de Caxiuanã - PA: Volume de Diagnóstico. Brasília, 2012. 314p. Disponível em: <http://www.icmbio.gov.br/portal/biodiversidade/unidades-de-conservacao/ biomas-brasileiros/amazonia/unidades-de-conservacao-amazonia/1928-flona-de-caxiuana.html> Acesso em: 05 dez. 2013.

DIEGUES, Antonio Carlos. Biodiversidade e comunidades tradicionais no Brasil. São Paulo: USP, 2000. 211p.

FEYRABEND, Paul. Contra o método. Rio de Janeiro: F. Alves, 1977. 487p.

MMA. Ministério do Meio Ambiente. Decreto Legislativo ${ }^{\circ} 2$ de 1994. Aprova o texto da Convenção sobre Diversidade Biológica. Brasília, 2000.30p.

MORIN, Edgard. Ciência com Consciência. 8.ed. Rio de Janeiro: Bertrand Brasil, 2005. 250p.

RODRIGUES, José Eduardo Ramos. Sistema Nacional de Unidades de Conservação. São Paulo: Editora Revista dos Tribunais, 2005. 205p.

SHIRAISHI NETO, Joaquim. Direito dos povos e das Comunidades Tradicionais no Brasil: Declarações, Convenções Internacionais e Dispositivos Jurídicos de uma Política Nacional. Manaus: UAE, 2007. 224p.

SILVA, Edson Vicente da. Geografia física, geoecologia da paisagem e educação ambiental aplicada: interações interdisciplinares na gestão territorial. Revista Geonorte, v.4, n.4, p.175-183, 2012.

SILVA, Márcio Luiz da. Paisagem e geossistema: contexto histórico e abordagem teórico-metodológica. Revista Geo-ambiente on-line, n. 11, p. 163-185, 2008.

STRAUSS, Claude Lévi. O pensamento selvagem. 8.ed. São Paulo: Nacional, 2008. 323p.

WWF/IPE. World Wildlife Foundation/ Instituto Ipê. Gestão de Unidades de Conservação: compartilhando uma experiência de capacitação. Brasília: Áttema Editorial, 2012. 393p. 